\title{
TRABALHO E EDUCAÇÃO: O ADOECIMENTO PSÍQUICO DOCENTE E AS IMPLICAÇÕES NA ORGANIZAÇÃO DO ENSINO
}

\author{
Fernando Wolff Mendonça ${ }^{i} \oplus 0000-0002-6193-4793$ \\ Universidade Estadual de Maringá - UEM \\ Léslie Amanda da Silva ${ }^{\text {ii }} \odot 0000-0003-0770-2710$ \\ Universidade Estadual de Maringá - UEM
}

Resumo: Na configuração do modo de produção capitalista, o adoecimento do trabalhador é fator que merece destaque. Com as reformas neoliberais para a educação após a Segunda Revolução Industrial, na segunda metade do século XIX, com os novos modelos de produção, os/as educadores/as foram perdendo suas identidades, não reconhecendo sua função social como mediador/a do ensino e aprendizagem, mas, atuando como percursor/a do sistema de capital. Atualmente, tem se aumentado a quantidade de professores/as diagnosticados/as com doenças psicológicas, levando à dependência de medicamentos, o que tem contribuído para o desinteresse e desmotivação no trabalho escolar. É por fatores como estes e por compreender a necessidade de estudos nesta temática, que esta pesquisa propõe realizar uma análise histórica do trabalho e dos modos de produção, para entender os fatores que motivaram o adoecimento dos/as trabalhadores/as, com ênfase no profissional docente e seu papel na educação. A pesquisa está fundamentada na Teoria Histórico-Cultural, tomando como base as análises referentes ao Materialismo Histórico-Dialético, compreendendo como as formas de trabalho, vinculadas ao sistema neoliberal, alienante e desumana contribui para a ineficácia do ensino, bem como sua organização.

Palavras-chave: Modo de Produção. Mal-Estar Docente. Organização do Ensino.

\section{WORK AND EDUCATION: THE TEACHING PSYCHIC DISEASE AND THE IMPLICATIONS FOR THE EDUCATION ORGANIZATION}

\begin{abstract}
In the configuration of the capitalist mode of production, or the commitment of the worker is a factor that deserves to be highlighted. With neoliberal reforms for education after the Second Industrial Revolution, in the second half of the 19th century, with new production models, they / as educators / as losing their identities, not recognizing their social function as a mediator / teaching and learning, but, acting as a precursor / capital system. Currently, there has been an increase in the number of teachers / as diagnosed / as psychological illnesses, leading to drug dependence, or that has contributed to disinterest
\end{abstract}

and demotivation in school work. It is due to factors like these and because it understands the need for studies on this theme, that this research carries out a historical analysis of work and production modes, in order to understand the factors that motivate or harm workers, with a professional and teaching focus. its role in education. A research is based on the HistoricalCultural Theory, adopting as a basis the analysis of Material-Historical-Dialectic, comprising as forms of work, linked to the neoliberal, foreign and inhumane system for the ineffectiveness of teaching, as well as its organization.

Keywords: Production Mode. Teacher malaise. Organization of Teaching. 


\section{Introdução}

Analisando o cenário político vigente na segunda metade do século XIX, os modos de produção que respaldavam a sociedade do período, bem como as transformações nas formas de trabalho e na vida dos trabalhadores, se viu uma necessidade de compreender o quanto o processo histórico contribuiu para a formação da sociedade atual, tendo a educação como base para desencadear novas percepções.

É por estar em contato com a área da educação, vivenciar suas conquistas e suas limitações que esta pesquisa tem como função social compreender os fatores que tem levado o adoecimento dos educadores/as e consequentemente afetado a organização do ensino.

Durante minha carreira como profissional na área da formação de professores, me deparei com professores/as que não se sentiam mais à vontade em estarem em sala de aula, menosprezavam os alunos, choravam durante as aulas, muitos/as torciam para que ficassem doentes para que saíssem de licença e ao serem questionados/as sobre os motivos que levavam a estes comportamentos, culpavam a família, o governo, os colegas de trabalho e até si mesmos/as pela má eficácia do ensino.

Percebendo estão, a necessidade de ajudar esses profissionais e ao mesmo tempo estabelecer relações com o ensino e aprendizagem dos alunos que este estudo bibliográfico, visa por meio de análises históricas amparar esses/as professores/as que se sentem sozinhos/as, culpados/as, sobrecarregados/as e desvalorizados/as, a reconhecerem sua importância social, se autoconhecerem como profissionais que atuam como mobilizadores/as do ensino e na formação humana.

As aquisições do desenvolvimento histórico das aptidões humanas não são simplesmente dadas aos homens nos fenômenos objetivos da cultura material e espiritual que os encarnam, mas são aí apenas postas. Para se apropriar destes resultados, para fazer deles as suas aptidões [...] A criança, o ser humano, deve entrar em relação com os fenômenos do mundo circundante através de outros homens, isto é, num processo de comunicação entre eles. Assim, a criança aprender a atividade adequada. Para sua função este processo é, portanto, um processo de educação (LEONTIEV, 2004, p. 290).

Como percurso teórico, foi utilizado a Teoria histórico-cultural, tendo como fundador L. S. Vygotski (1896-1934) e seus seguidores A.N. Leontiev (1903-1979) e A. R. Lúria (1902-1977). Esta teoria é dada a corrente psicológica, que explica o desenvolvimento da 
mente humana com base nos princípios do materialismo dialético. Portanto, no decorrer do texto as análises realizadas se remeteram nos princípios defendidos por Karl Marx (18181883), que defende que a concepção dos processos históricos se torna fundamental para a compreensão dos fenômenos sociais.

Portanto, a primeira seção promove uma análise a respeito dos modos de produção que permearam a segunda metade do século XIX, bem como as formas de mão de obra utilizadas e os sistemas de produção para acúmulo de capital. Ainda, analisaremos a determinação do modelo fordista/taylorista no direcionamento da educação ao longo do século XX, até chegarmos a crise deste sistema de acumulação, e as consequências e mudanças operadas pelo capital a fim de recompor seu padrão de acumulação, estabelecendo uma relação com os modelos de escola e a função social dos/as educadores/as neste período.

A segunda seção, estabelece uma relação intrínseca entre o trabalho e a educação, em que são apresentados os mecanismos de controle dos modos de produção na sociedade capitalista e o quanto a educação tem sido utilizada como refém. Para tanto, tonou-se necessário retomar os conceitos históricos de alguns documentos que foram desenvolvidos com o princípio de promover qualidade no ensino e que na realidade serviram ainda mais para que os/as professores/as e a escola fossem perdendo sua função social. A identidade do trabalhador foi se perdendo e sendo hoje, visto como profissional sem valor e o seu sucesso e o fracasso passaram a ser responsabilidade de si próprio, fatores como estes que contribuem para o adoecimento psíquico.

Nas considerações finais, é proposto a reflexão sobre os motivos e necessidades da aprendizagem, o papel das políticas públicas e a compreensão de que infelizmente, o esgotamento psicológico e físico que se encontram os profissionais da área da educação, são ocasionados em condições de alienação e condições de trabalho precárias, ambas provindas de um sistema capitalista de produção.

\section{Modos de produção e as formas de organização do trabalho}

Nesta seção retomaremos alguns fatos importantes sobre o modo de produção capitalista, enfatizando o sistema econômico Taylorista/Fordista- instaurado com a Segunda Revolução Industrial na segunda metade do século XIX e por fim o Toyotismo, utilizado nos dias atuais. 
Compreender tais processos econômicos é primordial, tendo em vista que é pelo trabalho que o homem faz o intercâmbio com a natureza, e que esta é transformada para produzir os bens materiais necessários para suprir os anseios humanos. Quando o homem a estabelece, fica intrínseca essa relação com a natureza, transformando-a, transforma a si mesmo.

De acordo com Tonet:

O trabalho distingue-se de todas as outras categorias, pois somente ele tem a função de produzir a riqueza material necessária à existência humana. Todas as outras categorias, a exemplo da arte, linguagem, ciência, educação, direito, política, religião, etc., embora dotadas de uma natureza e uma função social próprias têm sua origem no trabalho (TONET, 2012, p. 52).

Por isso, que entre o trabalho e as outras categorias existe uma relação ontológica, ou seja, as relações são construídas por fenômenos sociais, entretanto o trabalho permanece como base de qualquer sociedade.

No século XIX, por volta de 1860, a Revolução Industrial assumiu novas características, impulsionada por inovações técnicas, como a descoberta da eletricidade, transformação de ferro em aço, o surgimento dos meios de transporte e, mais tarde, dos meios de comunicação, o desenvolvimento da indústria química e de outros setores.

Com estas modificações ocasionadas no modo de produção, nasce a Segunda Revolução Industrial e, com ela, o anseio para o acúmulo de capital. De acordo com Silva (2005) neste período levou-se ao extremo a especialização do trabalho; surgiram as linhas de montagem, esteiras rolantes por onde circulavam as partes do produto a ser montado, de modo a agilizar a produção. Ampliou-se a produção, passando a produzir artigos em série, isto é, quanto mais se produzia mais se barateava o custo por unidade produzida.

Taylor e Ford foram os principais expoentes dessa nova forma de produção material dos bens de consumo. Cada qual desenvolveu suas teorias e práticas numa sociedade capitalista na qual a supremacia burguesa estava estabelecida na esfera econômica, o crescimento urbano era favorecido pelo êxodo rural acelerado e, desta forma, o aumento da classe operária era consequência natural. Ainda neste período, a política e a ideologia gravitavam entre dois polos: a burguesia industrial e o proletariado (SILVA, et al, 2005, p. 5)

\subsection{Taylorismo e Fordismo: do artesão para o operário}


À medida que as indústrias foram se ampliando, a competividade passou a ser fator predominante. Frederick Taylor, para melhorar sua produção, cria um sistema de organização industrial e administrativo no final do século XIX, sugerindo uma nova organização de trabalho, por meio da divisão de trabalho e investindo na especialização do trabalhador fabril, e assim, a produção de maximizaria. Neste período, havia nas indústrias muitos artesões que dominavam todos as etapas de processo de produção. Com a instauração do sistema Taylorista, o conhecimento do todo se perde e o/a trabalhador/a passa a conhecer apenas uma parte do processo. Muitas empresas começaram a utilizar esse sistema devido ao controle que se tinha da produção, os proprietários apenas observando o trabalho, constatava-se os problemas ocorridos.

A Teoria da Administração Científica iniciada por Frederick W. Taylor (1856 - 1915) fundamenta-se na aplicação de métodos da ciência positiva, racional e metódica aos problemas administrativos, a fim de alcançar a máxima produtividade. Essa teoria provocou uma verdadeira revolução no pensamento administrativo e no mundo industrial. Para o aumento da produtividade propôs métodos e sistemas de racionalização do trabalho e disciplina do conhecimento operário colocando-o sob comando da gerência; a seleção rigorosa dos mais aptos para realizar as tarefas; a fragmentação e hierarquização do trabalho (MATOS, et al, 2006, p. 2).

A crítica a esse sistema é a alienação que foi desenvolvida nos/as trabalhadores/as, tornando-os/as dependentes da empresa. Entretanto, como o importante na época era a produção e o acúmulo de capital, quanto mais se produzia mais se ganhava, não havia nenhuma preocupação com o/a trabalhador/a, a não ser, com sua motivação durante a produção.

Henry Ford se apropria das ideias de Taylor e implanta a automação. A indústria automobilística Ford implantada nos Estados Unidos foi a primeira fazer o uso das esteiras que levavam o chassi do carro a percorrer toda a fábrica. Com as esteiras, o/a trabalhador/a já não decide mais o tempo que leva para produzir, deve corresponder o tempo da máquina, se tornando uma extensão da maquinaria.

O fordismo foi caracterizado como a união entre o trabalho parcelado, fragmentado, com postos de trabalho fixos e a esteira, que levava as peças e componentes para o operário, acarretando uma economia de tempo para a produção. Os/as trabalhadores/as neste modo de produção, realizava tarefas simples que requeriam pouco treinamento.

Segundo Botelho (2016) com as inovações, o trabalho foi dividido no interior da fábrica, possibilitando a padronização das peças e, consequentemente elevando a 
especialização da mão de obra. Portanto, de acordo com o sistema Taylorista já utilizado, cada trabalhador/a em seu posto de trabalho fixo, realizaria apenas uma tarefa específica.

A ideia de Ford de produção em massa e consumo de massa só pôde se realizar a partir do momento em que uma classe operária forte exigiu uma parcela maior da riqueza gerada e a destinou ao consumo. As especificidades históricas do pós-guerra, principalmente a "ameaça comunista" também contribuíram para que a classe que vive do trabalho pudesse extrair maiores conquistas dos representantes do capital e do Estado (BOTELHO, 2016, p. 4).

A chamada ameaça comunista foi um termo utilizado por muitos/as conservadores/as, que pregavam a ideia de que se o comunismo chegasse ao poder, seria uma tragédia para a sociedade. Para que isso não ocorresse, a estratégia utilizada foi pagar o salário/bônus para o/a trabalhador/a de acordo com sua produção, assim, haveria trabalhadores/as motivados/as a produzir em grande escala, para que o salário que recebessem em troca, comprariam o produto que produziu.

As formas de organização da classe trabalhadora dependiam do acúmulo de trabalhadores/as na fábrica para serem viáveis, com as transformações nos países capitalistas avançados houve o declínio das velhas indústrias do século XIX e XX, fazendo com que reduzisse o número de trabalhadores/as nas fábricas, fragmentando as unidades de produção em pequenas unidades subcontratadas.

As relações sociais estão intimamente ligadas às forças produtivas. Adquirindo novas forças produtivas, os homens transformam o seu modo de produção e, ao transformá-lo, alterando a maneira de ganhar a sua vida, eles transformam todas as suas relações sociais. O moinho movido pelo braço humano nos dá a sociedade com o suserano; o moinho a vapor dá-nos a sociedade com o capitalista industrial (MARX,1985, p.125).

O modelo de produção taylorista/fordista com a produção em massa, começou a se preocupar com a falta de matéria-prima utilizada e os grandes estoques de produtos, ocasionando para a sociedade do período uma crise econômica.

Para o trabalho, reflete o insuficiente atendimento das necessidades sociais da maior parte das populações no mundo, os elevados índices de pauperização, a precarização e a flexibilidade das relações de trabalho, a intensificação da exploração e a emergência do fenômeno do desemprego estrutural. Torna-se evidente a incapacidade das forças econômicas de controlar, através do fordismo e das políticas keynesianas, as contradições imanentes ao desenvolvimento capitalista (SOUZA, 2012, p. 145). 
Originário no Japão, como solução para a crise do capital ocorridas em 1970 de dentro das fábricas de automóveis, o Toyotismo estendeu-se pelo mundo todo. Uma nova forma de organização industrial e de relação entre capital e trabalho surge das cinzas do taylorismo/fordismo. A Toyota reestrutura a organização de produção, ao invés de produzir em massa, a produção passa a ser por demanda, isto é, produzir de acordo com os anseios da sociedade, o que diminui os prejuízos.

De acordo com Alves (1994) “[...] a adoção do paradigma Toyotista é uma necessidade objetiva da lei da acumulação do capital nas condições vigentes sob o capitalismo tardio em crise (p. 27)".

Com a articulação logística denominada de Just in Time, envolvendo a produção, transporte e venda, o proprietário passou a aumentar seus lucros e ter maior controle do produto. Neste mesmo período os avanços tecnológicos e os meios de comunicações estavam em foco, muitos trabalhadores foram substituídos pelas máquinas.

A preocupação das empresas, eram produzir em demanda, entretanto que a cada produto houvesse inovação. Para isso, exigia-se novas qualificações do/a trabalhador/a, articulavam habilidades cognitivas e habilidades comportamentais.

\footnotetext{
Através da automação o mesmo trabalhador era encarregado de supervisionar mais de uma máquina ao mesmo tempo, aumentando o ritmo do trabalho e a produtividade, procurando a qualidade total em todas as etapas da produção e não somente, a qualidade seria controlada por um departamento único, especial e centralizado, como ocorria no fordismo (OLIVEIRA, 2004). Para manter seu emprego, o empregado era obrigado a se manter no limite, devendo aumentar a produtividade, ainda que houvesse a diminuição dos trabalhadores da equipe (BORGES, et al, 2011, p. 55).
}

Os modos de produção atuam como disciplinadores do trabalho, ocasionando a divisão de classes. A reestruturação capitalista se desenvolve como estratégia do capital para encontrar alternativas à sua crise estrutural nas últimas décadas do século XX e no início do século XXI. Todavia, mesmo com as constatações históricas dos efeitos nefastos da reestruturação capitalista sobre grande parte da sociedade, o capital investe diariamente em políticas ou propostas que capturam ideologicamente a classe trabalhadora, mascarando então as opressões, alienação e subordinação dos proletariados, como veremos na seção posterior.

\section{Trabalho e educação}


A humanidade vive hoje um momento claramente contrarrevolucionário. Marx deixou claro que a revolução que levaria a superação do capitalismo teria que ser uma revolução política com alma social, ao contrário de todas as outras revoluções sociais que tiveram alma política (TONET, 2012, p. 53), como as que ocorrem nos dias atuais.

Devido os modelos de produção existentes e o sistema econômico neoliberal, instaurado em 1994, com o governo de Fernando Collor de Mello e consolidado com a chegada de Fernando Henrique Cardoso à presidência, a classe trabalhadora foi afetada de maneira negativa, tanto em sua realidade material quanto ideológica.

O processo de alienação econômica, produto do desenvolvimento da divisão social de trabalho e das relações de propriedade privada, não tem portanto por única consequência afastar as massas da cultura intelectual, mas também dividir esta em elemento de duas categorias, umas progressistas, democráticas, servindo o desenvolvimento da humanidade, e as outras que levantam obstáculos a este progresso, se penetram nas massas, e que formam o conteúdo da cultura declinante das classes reacionárias da sociedade (LEONTIEV, 2004, p.295).

Acredita-se nesse sentido, que a educação passa a não efetivar sua função social de ensino, mas atuando como mecanismo de alienação cultural, com o intuito de priorizar os anseios do capital e dessa forma favorecendo a classe dominante. Os movimentos sociais que reivindicavam os direitos humanos, bem como, os dos/as trabalhadores/as, ainda são existentes. Entretanto, o objetivo dessas lutas não foram e não são infelizmente, o enfrentamento do modo capitalista de produção, com o anseio de superá-lo, mas apenas o desejo de obter ganhos que não desdobram a sua lógica.

Ao centrar a luta no campo da política - incluindo aí as lutas desenvolvidas no âmbito da economia, já que elas nunca seriam dirigidas à contestação radical da ordem social vigente - a classe trabalhadora aceitou que a disputa se limitasse apenas a questões internas ao modo capitalista de produção, deixando de lado o seu objetivo específico que é a superação do capital (TONET, 2012, p. 59).

O esboço de uma "retirada" da subjetividade do trabalhador, que foi sistematizado com o Toyotismo, já estava presente no Taylorismo/ Fordismo, porém não apenas do trabalhador das indústrias, mas a educação também estava presente neste cenário. Devido a esses fatores diante do contexto, a análise que a seguir será realizada é sobre o papel da educação neste período, ou seja, a escola cumpria sua função social? 
A educação é um poderoso instrumento de reprodução do capital. De acordo com TONET (2012) "Para o capital, dada a sua lógica, sua reprodução é a questão mais importante, mesmo que isso signifique a destruição da humanidade (p.62)". Com a complexificação da sociedade, a partir do desenvolvimento das forças produtivas e as consequências das relações sócias construídas, a educação atua como necessidade da humanidade para a sua própria reprodução e continuidade. Devido a instauração deste novo sistema econômico, o/a trabalhador/a e as formas de bem-estar do/a proletariado/a são insignificantes para o sistema, o objetivo é o acúmulo e ampliação de capital, entretanto a preocupação com a especialização e formação deste profissional começa a ser questionada, portanto, eis então a função da educação.

A partir destas exigências colocadas pelo desenvolvimento das forças produtivas, a escola passa a ser espaço também da classe trabalhadora, sendo que nos modos de produção anteriores era exclusiva das classes dominantes. Por conta dessas exigências, a burguesia vai difundir os ideais modernos de universalização, laicidade e gratuidade da educação (SANTOS, 2014, p. 77).

A educação passou a ser compreendida pela população trabalhadora como a única instituição que garantiria melhores condições de vida. Neste sentido passa a ter destaque a pedagogia tecnicista, que prevalecia aulas com centralidade em treinos técnicos, manuseamento de máquinas, domínio de habilidades, atitudes e conhecimentos específicos para suprir o novo modo de produção.

Nesta proposta, a relação professor-aluno acontecia de forma formal, ambos deviam cumprir funções pré-definidas por especialistas ou técnicos de educação, objetivando o bom desempenho. A função do/a professor/a era a transmissão de conteúdo a partir de um sistema instrucional eficaz aos resultados da aprendizagem. O/A aluno/a tinha o papel de receber, aprender e memorizar as instruções dadas pelo professor.

[...] as reformas da educação brasileira orientadas ao atendimento das necessidades postas pelo modelo de produção fordista/taylorista implementadas pelos acordos internacionais - deram à educação brasileira "uma função bem parecida com a realidade da indústria e passamos a ter um sistema educacional operando fabrilmente, e dessa forma, redefinindo as funções dos professores, exigindo novas 'habilidades e competências"” (SANTOS, 2014, p. 102).

Em virtude a este modelo de desenvolvimento, as realidades objetivas do/a professor/a são modificadas, os mecanismos de controle foram adquirindo caráter cada vez 
DOI 10.33872/revcontrad.vlnl.e009 | v. 1, n. 2 | Jul./Dez. 2020

mais centralizado, ou seja, tornando essencial que os/as profissionais e as escolas tivessem algumas competências, aliás, capacitaria os/as professores/as a formar os/as futuros/as trabalhadores/as com as habilidades necessárias para o processo de industrialização.

No período de produção Fordista/Taylorista a escola se dividiu em dois grupos: o ensino dos/as proletariados/as e o ensino para os/as proprietários/as. Quando pensamos nesta divisão, nos remetemos as ideias de Marx, ao discutir as divisões de classes, para os que nasceram no primeiro grupo o destino é obedecer e ofertar mão de obra, por troca de um salário. Aqueles/as que possuem o destino em pertencer ao segundo grupo, o intuito é que o ensino possibilite que estes continuem em sua posição hierárquica, ou seja, os que mandam.

A população é uma abstração se desprezarmos, por exemplo, as classes que a compõem. Por seu lado, essas classes são uma palavra vazia de sentido se ignorarmos os elementos em que repousam, por exemplo: o trabalho assalariado, o capital etc. Estes supõem a troca, a divisão do trabalho, os preços etc. O capital, por exemplo, sem o trabalho assalariado, sem o valor, sem o dinheiro, sem o preço etc., não é nada (MARX apud NETTO, 2011, p. 4142).

A partir da reestruturação produtiva do capital, houve uma mudança na organização do sistema fabril. Com o Toyotismo, a educação passa a "garantir" a sociedade empregabilidade, entretanto, o indivíduo é o responsável por essa garantia. Quanto melhor for seu desempenho escolar, melhor será o cargo que ocupará no mercado de trabalho, característica essa do sistema neoliberal.

No Brasil, o neoliberalismo ganha força e expressão apenas nos fins dos anos 1980. Com o fim do regime militar (1985) e no bojo do processo de redemocratização do País, ocorre então, uma renovação do movimento sindical, com conquistas de novos direitos trabalhistas e previdenciários, presentes na constituição de 1988. Tendo em vista a necessidade de modernização do país, comparado aos padrões de países internacionais, o Brasil teve forte influência financeira do Fundo Monetário Internacional (FMI), Banco Mundial (BM) e Banco Interamericano de Desenvolvimento (BID).

De acordo com SANTOS (2014), as reformas no sistema educativo brasileiro tiveram uma clara influência a partir da conferência Mundial sobre Educação para Todos, realizada em Jomtien (Tailândia) em março de 1990. Essa conferência possibilitou novas orientações para as reformas educacionais dos países mais pobres e populosos do mundo (p. 113)

Nesse sentido a educação é vista como a principal maneira de distribuir renda e garantir mobilidade social. 
A referida recomendação do Banco Mundial está subsidiada numa pesquisa que assevera que o investimento na educação básica - oito anos no máximo para cada indivíduo (segundo a estimativa realizada na década de 1990, em que foram produzidas as recomendações e também na qual foi aprovada a LDB) - traz maior retorno econômico (SANTOS, 2014, p. 117).

Desta maneira, é evidente que para o Banco Mundial é desinteressante economicamente investir por muito tempo em educação, devido ser indivíduos que segundo os documentos não são competentes intelectualmente para um curso técnico, para estes são oferecidos apenas o ensino fundamental.

As mudanças produzidas na educação brasileira para adequá-la aos novos modos de produção não tiveram apenas interferência nas legislações, mas também nos modelos organizacionais pedagógicos, seus objetivos e conteúdo. A gestão e as formas de avaliar o sistema educativo também foram modificados, em que o Estado assume a função de avaliador da educação, utilizando instrumentos de controle, como o Fundo de Manutenção e Desenvolvimento do Ensino Fundamental e de Valorização do Magistério, a regularidade e a ampliação dos exames nacionais de avaliação (SAEB, ENEM, ENC) etc.

O/A professor/a neste cenário passa a ser avaliado, bem como sua produção, excelência e eficiência, entretanto, não se fala sobre a valorização do trabalho docente. Diante dessas reformulações e da descentralização do estado, os/as professores/as indo contrários aos novos modelos neoliberais, sofreram as consequências, tendo que aceitar gratificações de desempenho, o que acarretou salários sem reajustes.

Conforme pontua SANTOS (2014, p.122) "No plano simbólico, os professores foram intensamente acusados de corporativismo, desqualificando-os e resultando na construção de uma imagem extremamente negativa para esta categoria profissional".

Devido a estes acontecimentos, houve um declínio da profissão docente, decorrente da flexibilização da prática. O trabalho docente atua para suprir as demandas do sistema, cabendo a tarefa de racionalizar o contato dos alunos com os materiais instrucionais, dos livros didáticos aos multimidiáticos.

Os/As professores/as assumem novas funções no processo educativo, seu trabalho não é caracterizado apenas pelas atividades em sala de aula, mas passam a estarem inseridos no trabalho de gestão, formulação e planejamento de projetos. O que caracteriza o/a professor/a é o quanto de conhecimento possui e pode transmitir, neste modelo Toyotista, essa é a única forma de valorização existente. 
Tal sentimento talvez explique tanto mal-estar manifestado pelos professores de que precisam saber cada vez mais, de que lhes faltam cursos e programas de qualificação, razão de tantas demandas pautadas pelos sindicatos dos trabalhadores docentes por maiores investimentos em formação continuada (OLIVEIRA, 2003, p. 32 apud SANTOS, 2014, p. 125).

Nos dias atuais estes profissionais são coagidos a desempenharem funções de agente público, assistente social, enfermeiro, psicólogo, além das funções familiares. Essas funções retiram suas identidades e acabam possibilitando a desqualificação e a disfunção do seu papel como educador/a, constatando perante a sociedade que ensinar não é mais primordial para o/a professor/a.

\subsection{O mal-estar docente}

De acordo com Mendonça (2017) os baixos índices de qualidade de educação geram a necessidade de superar os aspectos negativos relativos ao ensino, para tanto se utiliza o temo de "qualidade total", conceito este utilizado devido o modo de produção Toyotista (p. 72). A competitividade é visível, exige que o professor cumpra a função de gerador da formação docente, isto é, o/a profissional é o/a responsável pelo seu sucesso ou fracasso.

Mendonça (2017) ainda afirma que as políticas de formação do professor desde os anos de 1990 até a atualidade, têm contribuído para que esse profissional encontre dificuldades para adquirir uma formação sólida para atender à formação de seus alunos (p. 76).

As políticas oriundas de 1990 que destinam ao trabalho docente, não visam a qualificação e valorização do seu trabalho, mas contribuem para responsabilizar ainda mais o docente. Um exemplo é o Relatório Delors, publicado no ano de 1996, que colocava em segundo plano a transmissão e aprendizagem dos conhecimentos científicos.

Algumas teorias pedagógicas existentes nos dias atuais, correspondem aos enfoques pontuados pela pedagogia do aprender a aprender, tornando o ensino condizente com os parâmetros burgueses. A prioridade está, em que o indivíduo necessita aprender a se adaptar as modificações ocorridas na sociedade e se tornar coerente com os modos de produção existentes.

Ao nos remetermos a psicologia marxista de Vygotsky, compreendemos que quando a educação passar a desconsiderar as relações sociais construídas em um processo histórico, ela perde sua totalidade. Para tanto, é essencial o estudo da psique uma vez que a distância entre as relações econômicas e as formações ideológicas se faz cada vez maior. 
Desta forma, TULESKI (2008) pontua que:

[...] uma psicologia que não leve em consideração as relações entre os homens em sociedade seria pura abstração. [...] A condição para a construção de uma psicologia marxista no campo teórico era o domínio e a utilização do método proposto por Marx, pois sem ele está se transformaria em uma colcha de retalhos, semelhante à psicologia burguesa (TULESKI, 2008, p. 118).

Fica evidente que estas pedagogias servem apenas para retirar do decente sua identidade e função como mediador do ensino aprendizagem. O/A professor/a passa a assumir funções que não são condizentes com a sua função, isto é, a transmissão de conhecimento cientificamente elaborado, tornando apenas facilitadores do processo de ensino.

Essa desvalorização e a disfunção do trabalho docente, oriundos dos modos de produção feudal e reforçados com as condições objetivas impostas pelas reformas educacionais na década de 1990, tem acarretado nesses profissionais o aparecimento de adoecimentos psíquicos.

Os problemas de saúde que atingem a categoria mantêm intimas relações com um conjunto de fatores, entre os quais se destacam: o tipo de trabalho exercido, considerando-se a responsabilidade pela formação de outros sujeitos; o excesso de trabalho; a precarização do trabalho, a perda de autonomia, a sobrecarga de trabalho burocrático, ao quadro social e econômico e às condições de vida dos alunos (SANTOS, 2014, p. 130).

Devido a estes fatores, muitos/as professores/as têm se afastado das salas de aula, ocasionando a falta de profissionais nas instituições de ensino e então, tornando o ensino prejudicado, pois para suprir a demanda de alunos, muitos profissionais são substituídos por trabalhadores/as desqualificados/as para atuar em salas de aula.

Compreendemos que esse adoecimento é oriundo das condições objetivas do trabalho contemporâneo, o profissional tem se tornado refém do sistema, sendo atacados diariamente pelas reformas educacionais e legislativas, além das pressões que sofre pelo mercado.

A noção de profissional é constituída por determinações históricas sociais. As lutas travadas pela categoria dos trabalhadores em educação por melhores salários e condições adequadas de trabalho representam, também, a luta pelo reconhecimento profissional, por parte do estado, a fim de obter o mesmo padrão funcional e prestigio de outras categorias como medicina e direito (BERTOLDO et al, 2012, p. 106). 
DOI 10.33872/revcontrad.vlnl.e009 | v. 1, n. 2 | Jul./Dez. 2020

É um reconhecimento que anseia ser conquistado por muitos profissionais de diversas categorias, seja de ensino público ou privado, entretanto se torna preocupante o processo formativo dos alunos, certo de que a um crescente número de professores/as adoecidos/as, que por necessitarem trocar sua mão de obra por um salário, estão em salas de aulas doentes e acabam de certa forma afetando o ensino e impossibilitando o bem-estar dos educandos.

\section{Considerações finais}

Diante dos estudos históricos apresentados, fica explícito o quanto os profissionais estão submetidos a condições alienantes, estressantes, exaustivas, que tem possibilitado sofrimento psíquico.

Com as reformas ocasionadas pelos modos de produção capitalista, que invadiram os sistemas escolares e as formas de relações sociais, em que se dividiu a sociedade entre os proprietários e os proletariados, transformou o artesão em operário, o/a professor/a em percursor/a do sistema capitalista e que a escola perde sua função de transmitir o conhecimento científico, são fatores predominantes para a compreensão do desgaste psíquico que permeiam a sociedade trabalhadora atual. As legislações foram e são constituídas de acordo com os anseios do Banco Mundial e demais instituições internacionais.

As formas de ensino recebem críticas diariamente, a queixa escolar e os problemas de aprendizagem são abrangentes, professores/as e alunos/as estão desmotivados e adoecendo e não se observa políticas que acolham esses indivíduos.

Até mesmo o planejamento de ensino que deveria ser algo de maior "valor" nas escolas, hoje é esquecido. Planejar um ensino que contemple a todos os alunos é algo que exige tempo e organização, o que para muitos docentes que já se encontram em exaustão psíquica, se torna algo estressante e trabalhoso e é por este motivo que precisamos pensar nas necessidades dos nossos alunos, pois também se encontram cansados das monotonias das aulas.

Não há sentido para educação e não se gera motivos para a aprendizagem. Esse cenário tem sido discutido por todos, gerando críticas e queixas em relação ao ensinoaprendizagem, aos professores e alunos, em que se culpa a família pela não participação escolar, os professores pela falta de paciência, os educandos pelo mau comportamento, o sistema escolar pela desvalorização com os profissionais, ou seja, o maior anseio é encontrar o culpado pelo esvaziamento da educação, sem pensar nos reais determinantes dessa situação. 
Quando analisamos as políticas públicas destinadas a educação, como os programas de formação de professores e os sistemas avaliativos, percebemos o quanto esses documentos correspondem a ideia de mercado, isto é, se exige a produção do professor, as melhores notas dos alunos, mas não se destina recursos que respaldem o que é solicitado, deixando para segundo plano, a importância da formação do sujeito considerando sua condição cultural, social, psicológica e física.

O cuidado com a saúde mental, não deve apenas ser condição particular e restrita dos/as professores/as, mas deveria ser algo trabalhado pelo sistema escolar e governamental, de forma que ajude esse profissional a lidar com o seu mal-estar e assim, contribuir para melhoria do ensino-aprendizagem dos educandos.

Esta pesquisa possibilita novos estudos e afirma a necessidade de que novas pesquisas sejam realizadas nesta temática, oportunizando diferentes metodologias a serem utilizadas.

\section{REFERÊNCIAS:}

AQUINO, O. F. Concepção didática da tarefa de estudo: dois modelos de aplicação. In: Anais da $37^{\mathrm{a}}$ Reunião Nacional da ANPEd, 2015, UFSC, Florianópolis, 2015. Disponível em: http://37reuniao.anped.org.br/wp-content/uploads/2015/02/Trabalho-GT04-3570.pdf Acesso em: 08/09/2020.

BATISTA, É. Fordismo, taylorismo e Toyotismo: apontamentos sobre suas rupturas e continuidades. Londrina, 2015. Disponível em: <http://www.uel.br/grupopesquisa/gepal/terceirosimposio/erika_batista.pdf >. Acesso em: 23 ago. 2018.

BERTOLDO, E.; MOREIRA, L. A. L.; JIMENEZ, S. Trabalho, educação e formação humana: frente à necessidade histórica da revolução. São Paulo: Instituto Lukács, 2012.

LEONTIEV, A. O desenvolvimento do psiquismo. São Paulo: Centauro, 2004.

LEONARDO, N. S. T.; LEAL, Z. F. R. G., FRANCO, A. F. O processo de escolarização e a produção da queixa escolar: reflexões a partir de uma perspectiva crítica em psicologia. Maringá: EDUEM, 2014.

LIBÂNEO, J. C. A teoria do ensino para o desenvolvimento humano e o planejamento de ensino. Revista Educativa, v. 19, n. 2, p. 353-387, maio/ago. 2016. Disponível em: http://www.cascavel.pr.gov.br/arquivos/17012018_a_teoria_do_ensino_para_o_desenvolvime nto_humano_e_o_planejamento_de_ensino.pdf Acesso em: 08/09/2020.

LIBÂNEO, J. C.; FREITAS, R. A. M. Vygotsky, Leontiev, Davydov - Três aportes teóricos para a teoria histórico-cultural e suas contribuições para a didática. In: Anais do IV Congresso Brasileiro de História da Educação. 2006. Eixo temático 3. Cultura e práticas escolares. Disponível

em: http://www.sbhe.org.br/novo/congressos/cbhe4/individuaiscoautorais/eixo03 Acesso em: 08/09/2020.

MENDONÇA, F. W. A organização da atividade de ensino pelo professor alfabetizador. Curitiba: CRV, 2017. 
NETTO, J. P. Introdução ao estudo do método de Marx. São Paulo: Expressão Popular, 2011.

PAUlA, E. M. A. T.; MENDONÇA, F. W. Psicologia do Desenvolvimento. Curitiba: IESDE, 2009.

SANTOS, D. A. Contribuições da Psicologia histórico-cultural para a compreensão do adoecimento e sofrimento psíquico dos professores. Maringá, 2014. Disponível em: <http://www.ppi.uem.br/arquivos-para-links/tesese-dissertacoes/2014/diego >. Acesso em: 23 ago. 2018.

TULESKI, S. C. Vygotski: a construção de uma Psicologia Marxista. Maringá: EDUEM, 2008.

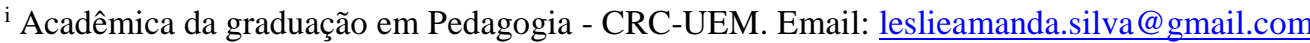

ii Doutor em Educação (UEM). Professor adjunto do departamento de Pedagogia e do Programa de PósGraduação em Psicologia da UEM. Email: ferwmen@ hotmail.com 